The International Journal of Engineering and Science (IJES)

|| Volume || 6 || Issue || 4 || Pages || PP 40-45|| 2017 ||

ISSN (e): 2319 - 1813 ISSN (p): $2319-1805$

\title{
Design of Early Flood Warning System
}

\author{
${ }^{1}$ Namrata Tiwari, ${ }^{2}$ Aakansha Singh, ${ }^{3}$ Nivedita Singh,${ }^{4}$ AmitabhSrivastava \\ ${ }_{1,2,3,4}$ Department of ECE, United College of Engineering and Management, Allahabad, INDIA
}

\begin{abstract}
From a national economic viewpoint, floods, both riverine and coastal, are the most destructive category of natural hazards in India. The economic losses to homes and personal property, to crops, business facilities and stock, utilities are major manifestations of flood losses. India is highly vulnerable to floods. in that scenario there is a urgent requirement for development and installation of enhanced flood forecasting sites in various commonly flooding regions. In this paper, we describe the design and implementation of a sensor-based embedded system for flood management. The project is mainly concerned on how the data of the flood is being used and analyzed for future forecasting. The Embedded system acquires many types of electronic devices such as GSM, Level sensor and many other to be deployed at remote locations, wherever mobile network is available. Collection of data occurs at user defined intervals of time and is to uploaded to the database the information acquired into the database can then be easily viewed from anywhere, used for further analysis . The system is being designed on MATLAB Software for the ease of analysis.
\end{abstract}

Keywords-Flood damage, GSM, MATLAB Software.

Date of Submission: 14 April 2017

$\longrightarrow$

Date of Accepted: 30 April 2017

\section{INTRODUCTION}

Flooding occurs when extreme volume of water is dried by rivers, creeks and many other geographical features into areas where the water cannot be drained adequately. Often during times of heavy rainfall, drainage systems in residential areas are not adequate, or unchecked civil development severely impedes the functionality of an otherwise acceptable drainage system.

Floods cause extremely large numbers of fatalities in every country, but due to India's extremely high population density and often under-enforced development standards, large amount of damages and many deaths which could be otherwise avoided, are allowed to happen. India witnesses flood due to excessive rain which then results in overflow of rivers, lakes and dams, which adds to cause large amounts of damage to people's lives and property. In the past, India has witnessed many of the largest, most catastrophic floods, causing irreparable damage to people's livelihood, property, and crucial infrastructure

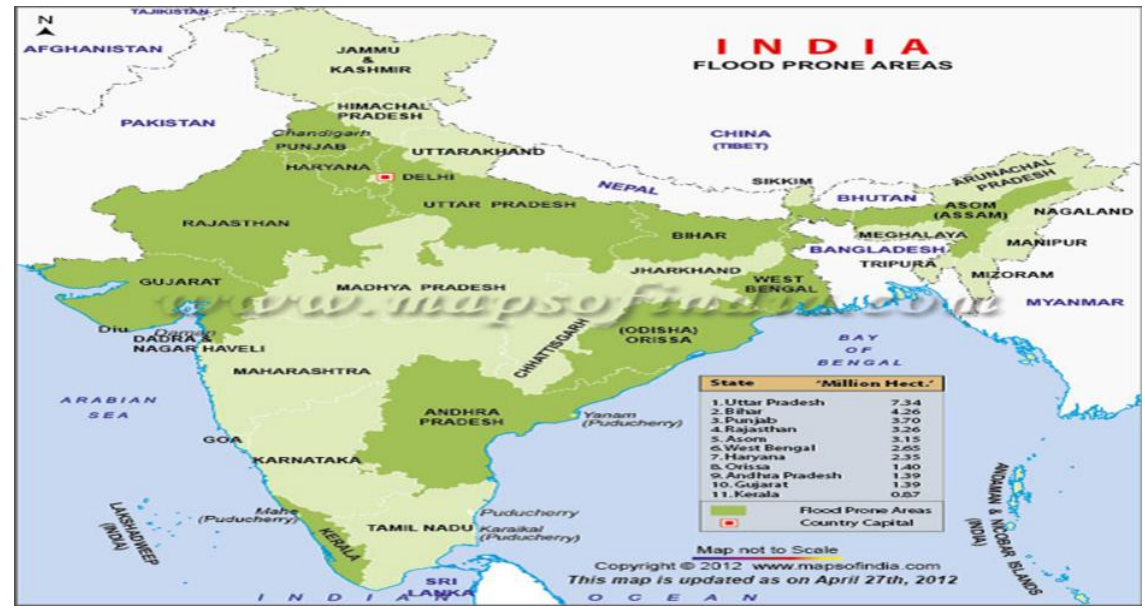

Fig (a) - Above figure shows sates which are more prone to floods

The states falling within the periphery of "India Flood Prone Areas" are West Bengal, Orissa, Andhra Pradesh, Kerala, Assam, Bihar, Gujarat, Uttar Pradesh, Haryana and Punjab. The intense monsoon rains from southwest causes rivers like Brahmaputra, Ganga, Yamuna etc. to swell their banks, which in turn floods the adjacent areas. 
The problem of flood is one of the main concerns now a day so there is a huge requirement to analyze the problem and to find the solution. The project is being implemented with the help of MATLAB software we use to analyze the system with the help of GSM installed which works to transmit and receive the information.

Floods are caused by many factors (or a combination of any of these): heavy rainfall, highly accelerated snowmelt, severe winds over water, unusual high tides, tsunamis, or failure of dams, levees, retention ponds, or other structures that retained the water. Flooding can be exacerbated by increased amounts of impervious surface or by other natural hazards such as wildfires, which reduce the supply of vegetation that can absorb rainfall. Periodic floods occur on many rivers, forming a surrounding region known as the flood plain. Flooding has many impacts. It damages property and endangers the lives of humans and other species. Rapid water runoff causes soil erosion and concomitant sediment deposition elsewhere (such as further downstream or down a coast).

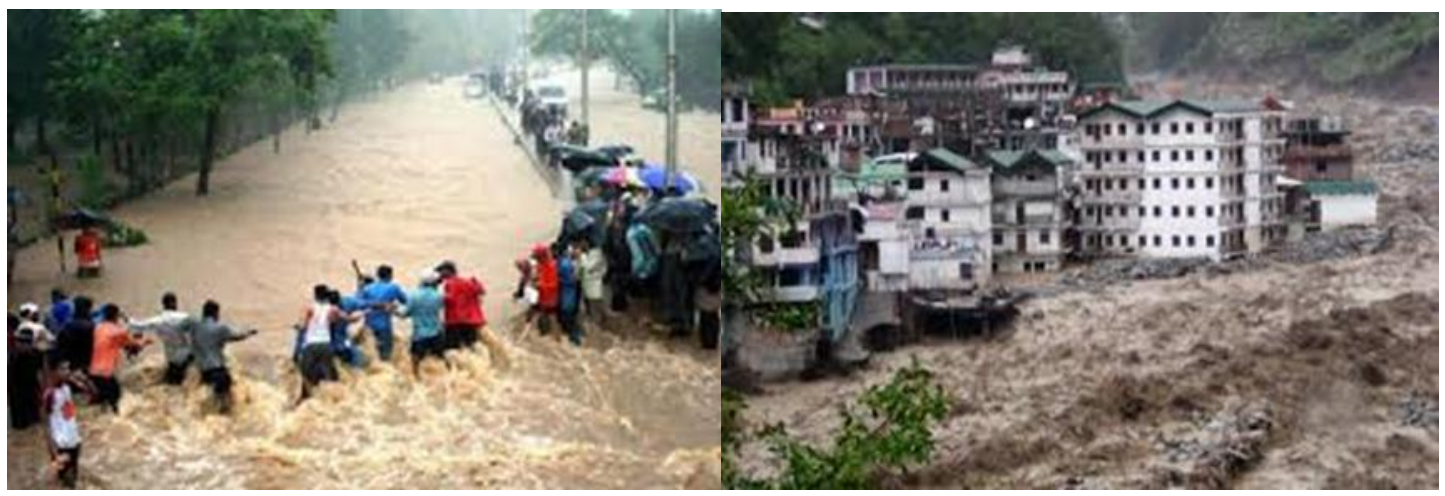

Fig-(b) and (c) above shows how much damage it can prevails to the society.

Rivers, especially big ones, can cause a lot of mayhem. When they flood, they destroy livelihoods, cause economic damage and kill people. It's no surprise then that humans, being the clever creatures that we are, try and stop rivers from flooding using whatever resources we have. Unfortunately, rivers, like most things in nature, are powerful and unpredictable. Stopping rivers from flooding full stop isn't possible but we can do a lot to mitigate and manage the risks that arise from flooding.

\section{LITERATURE REVIEW}

Researchers and engineers in the world have taken various approaches to the design of a flood management system. The Susquehanna Flood Forecast and Warning System (SFFWS), which is one of U.S premier flood warning systems, provides advanced flood/flash flood warning for residents of the 27,500-square-miles SusquehannaRiver Basin. Its foundation is anetwork of more than 60 stream gages and 70 rain gages that read, record, and transmit critical hydrologic data, which is transmitted from the field by way of the GOES (Geostationary Orbiting Environmental Satellite) satellite network, for incorporation into hydrologic models that provides river forecasts at stream gages[1]. Chen-hang Yen [2] had designed project to create an inexpensive flood detection system to monitor rising water in remote locations or residential areas. Inyiama [5] discussed to investigate and to improve understanding of the causes and circumstances of flood disaster deaths . since in our case, we use wireless electronic gages, with a wireless communication module capable of transmitting acquired data to our flood management dedicated server through a custom data queue service. This not only helps reduce the cost of implementation, but also enhances maintainability due to the low power requirement of on-field sensor module. Though, this approach allows the sensors to be deployed at any desired location, the system developed in this project has low power requirements, is more maintainable, and is extremely low-cost. Our system does not follow a multi-tiered approach which should lead to lower latency, and requires lesser resources $[1,2]$.

\section{SYSTEM DESIGN}

The system architecture of the system design is given in figure. The flood parameters likewater pressure, water level, flow etc. are measured by the sensor. The output voltage from thesensor is given to the MATLAB SOFTWARE which then works to analysis the water level after the analysis when the water level reaches to the danger level it works to send the date to the other GSM module and a alarm will start blow as soon as the level of water exceeds the maximum level of water flow in the river. 


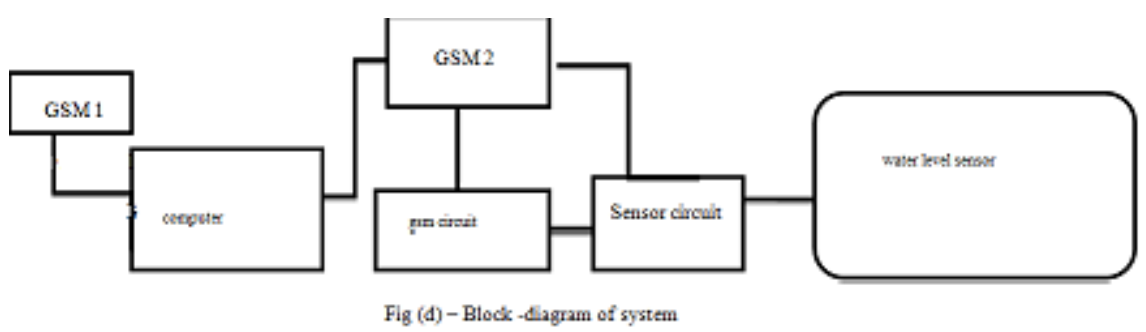

Fig (d) - Block -diagram of system

\section{MODULE DESIGN}

The different components or block of the system design are:-

I.GSM

II. WATER LEVEL SENSOR

III.BUZZER

\section{GSM MODULE}

GSM/GPRS module is used to establish communication between a computer and a GSM-GPRS system. Global System for Mobile communication (GSM) is an architecture used for mobile communication in most of the countries. GSM/GPRS MODEM is a class of wireless MODEM devices that are designed for communication of a computer with the GSM and GPRS network. It requires a SIM (Subscriber Identity Module) card just like mobile phones to activate communication with the network. A GSM/GPRS MODEM can perform the following operations:

1. Receive, send or delete SMS messages in a SIM.

2. Read, add, search phonebook entries of the SIM.

3. Make, Receive, or reject a voice call.

The MODEM needs AT commands, for interacting with processor or controller, which are communicated through serial communication. These commands are sent by the controller/processor. The MODEM sends back a result after it receives a command. Different AT commands supported by the MODEM can be sent by the processor/controller/computer to interact with the GSM and GPRS cellular network.

It is also Compatible with ARDUINO, RASPBERRY PI, ARM, AVR, PIC, 8051, etc. - Can also be directly connected to computer via Serial Port (Use GSM Tester or write your own Software). Best suited for GSM based Microcontroller Projects (better than SIM300 and other GSM Modems) Option for connecting MIC and SPEAKER directly to GSM MODEM for calls (LINE IN also available) Supportscommunication through RS232 with DB9 Connector, TTL Pins \& I2C Pins CALL SMS GPRS facility - MIC input, LINE input \& SPEAKER output pins.

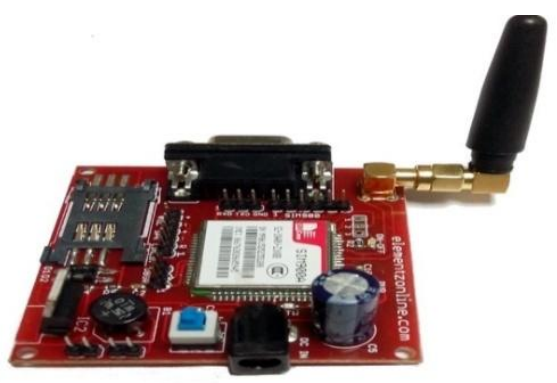

Fig(e)- showing the GSM module

\section{WATER LEVEL SENSOR:-}

The water level which we are using is Normally Close Typeand Corrosion Free Material with Advance Magnetic Technology this level sensor operates mainly on 2 to $12 \mathrm{~V}$ DCand Current 5 to $50 \mathrm{~mA}$ DC,its Maximum Switch Current is $500 \mathrm{~mA}$ (DC) and Maximum Switch Watt is $10 \mathrm{~W}$. Water level is measured in three different level by using this sensor Water level sensor is typically used to measure the depth/level of liquid in a container. As the water rises and reaches the highest.level of which is also known as the danger level it works to send the message to the GSM. 


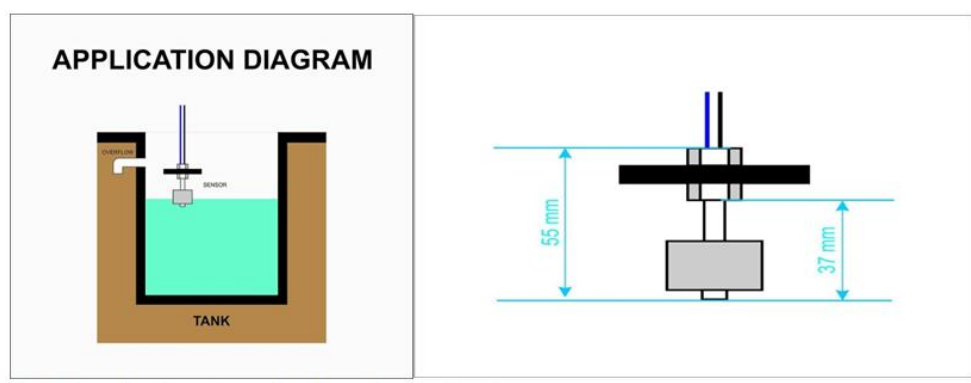

Fig (e) and (f) showing the schematic view of water level sensor

\section{BUZZER:-}

A buzzer or beeper is an audio signaling device which may be mechanical, electromechanical, or piezoelectric. Typical uses of buzzers and beepers include alarm devices, timers, and confirmation of user input such as a mouse click or keystroke. In this system we have applied the buzzer which works to make alarm when the level of water increases the maximum level it will start make buzzing sound to signify that the level of water has increased.

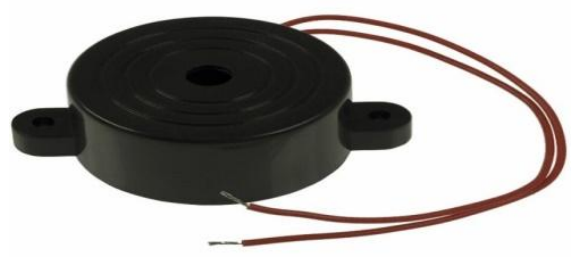

Fig (g) showing the buzzer used as an alarm

\section{WORKING}

In the water reservoir (river,dam, tank) the level sensor will be installed.They will work like a switch, as the work of the sensor will be connected in circuit. When water level in reservoir starts to approach respective levels, the sensors that are installed in the tank starts to get activated one by one indicating the water level in the water reservoir [6]. As water approaches to different levels it will always send the message to the configured mobile number which is being used by GSM Module. As the level of water reaches to the danger level a alarm will start alarming along with the message in the mobile phone.

\section{THEORITICAL CALCULATIONS}

Since we have used a measuring scale to identify the level of water at various points, At level 0 , which is also known as the "Ground Level" the value will be given as , LEVEL $0=1$ At level 1 , which is also known as the "Medium Level" the value will be given as, LEVEL $1=4$ At level 2, which is also known as the "High Level" the value will be given as, LEVEL $2=6$

\section{WATER AT LEVEL OVIII. WATER AT LEVEL 1}
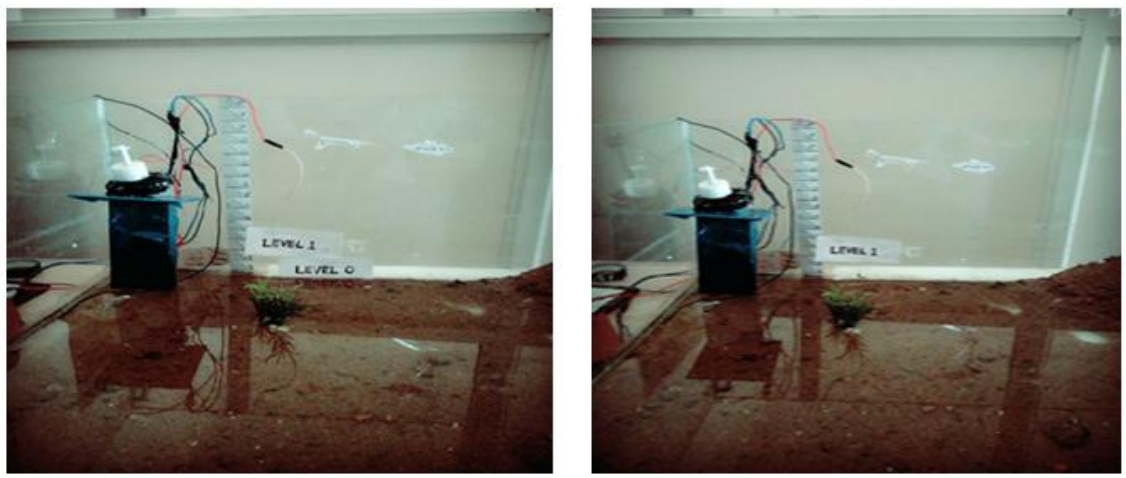
VIII. WATER AT LEVL 2

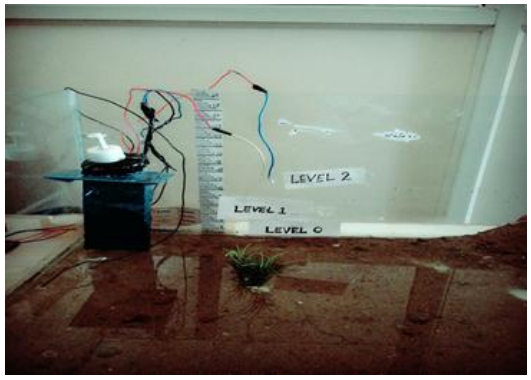

IX. PROJECT DESIGN
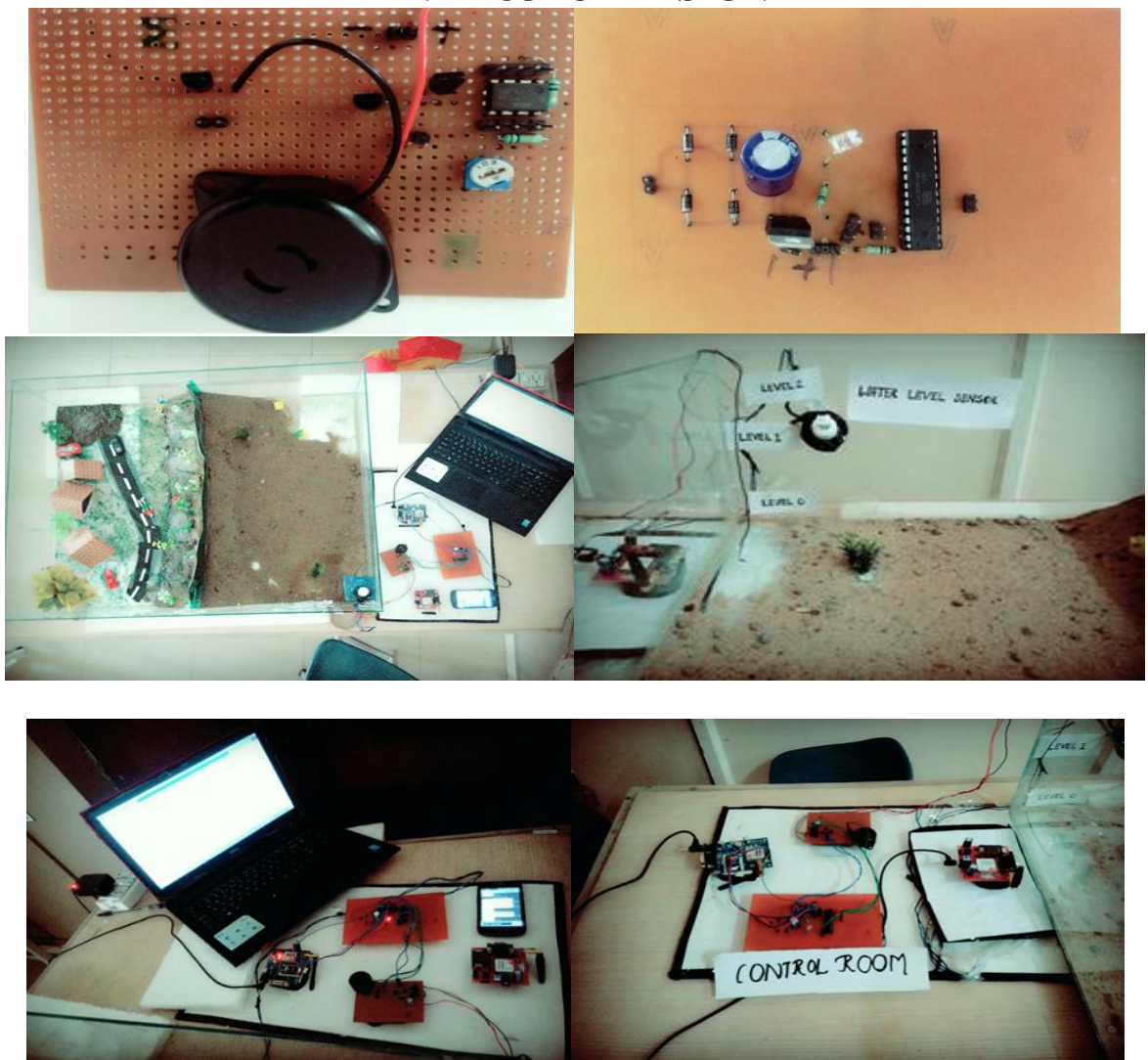

X. ADVAnTAgeS

1. This system will be very helpful when it is being deployed practically, using the MATLAB software its user interface has become very user friendly

2. The system will also help to sense the upcoming floods and helps to take preventive measures so as to minimize the risk of damage to people and property.

3. The Global Positioning System installed in the system will give the Message in whenever the level of water in the river reached to the danger level and sends the message to the number so as to help the government authorities to take right action.

4. The system also being helpful to relocate the people to other place whenever such a condition prevails.

\section{CONCLUSION}

In this project embedded system on flood monitoring is designed and implemented using GSM Modem and LEVEL SENSOR. The system is implemented and tested in the laboratory. The output result is obtained and being verified by cross checking it with the help of buzzer as an alarm to signify the danger level when the water get increased and also display on the LCD. This design can be of great help in real life in the flood prone area especially near the river and dam.

\section{ACKNOWLEDGEMENT}

The authors are grateful to United College of Engineering and Management for providing resources at the Department of Electronics and Communication Engineering to enable them to carry out this research work. 


\section{REFRENCES}

[1]. SubhajitSahu, Design and Implementation of a Heterogeneous Sensor-based Embedded System for Flood Management, InternationalJournalofEngineeringTechnology, ManagementandAppliedSciences.

[2]. Chen-hang Yen "Low-Cost Wireless High Water Detection System" at MEng Field Advisor: Bruce Land Date: January, 2014

[3]. Vardhanwagh, ketanpawar, Pratik patil, FPGA Implementation of Flood MonitoringSystem, International Journal of Engineering Technology, Management and Applied Sciences.

[4]. Stanley A. Changnon, Jr., Richard J. Schicht, and Richard G. Semonin ,A Plan For Research OnFloods and their mitigation in the United States.

[5]. Inyiama H. C., Obota M. E., Designing Flood Control Systems Using Wireless Sensor Networks, InternationalJournalofEngineeringResearch and Applications.

[6]. Prof. (Dr). Ajay Thakare, Miss TanwiDeshmukh, A review on "Implementation Of Integrated System to Avoid Flood Like Situation" , InternationalResearch Journal of Engineering and Technology. 